

\title{
ASSESSMENT OF STRESS AND ITS COPING MECHANISM AMONG LADY HEALTH WORKERS' OF JACOBABAD, SINDH
}

\section{Muhammad Ibrahim Ansari ${ }^{1}$, Chaudhary Muhammad Amjad ${ }^{2}$, Sadia Anwar ${ }^{3}$, Aisha Umer ${ }^{4}$, Muhammad Ismail Ansarí, Muhammad Siddique $^{6}$}

\author{
${ }^{1}$ Researcher SMBB Medical University Larkana, Sindh \\ ${ }^{2}$ Assistant Professor, Health Services Academy, Islamabad \\ ${ }^{3}$ Assistant Professor, Sindh University, Jamshoro \\ ${ }^{4}$ M. Phil Scholar, University Institute of Public Health, Lahore \\ ${ }^{5}$ Shah Abdul Latif University, Khairpur-Sindh \\ ${ }^{6}$ Department of Pharmacy, LUMHS Jamshoro-Sindh \\ Correspondence: Muhammad Ibrahim Ansari. Email: c6adetccl@yahoo.com
}

\begin{abstract}
Background: LHWs' are the backbone of community interventions related to health. our objectives were to assess association of work stress with demographic variables and to explore the coping mechanisms of LHWs to deal with work stress

Methods: Mixed method cross sectional study conducted in Jacobabad (Taluka Jacobabad, Garhi Khairo and Thul) District among Lady Health Workers during 05 months (Nov 2016-March 2017). Sample size was 78. SRQ-20, a WHO inventory was used. The data was analyzed in SPSS IBM 21.0 and 3 Focus Group Discussions were conducted for quantitative assessment. Qualitative component was recorded and themes were generated by inductive content analysis method

Results: Response rate was 96\%. Mean age, monthly income, and job experience were calculated as $35.59+7.995$ years with 20500 PKR and $4.87+3.599$ years of experience. The association in between age and subjective perception, education and physiological alteration and job experience with subjective perception were found significant as $\mathrm{p}=0.000, \mathrm{p}=0.45$ and $\mathrm{p}=0.11$. The responses of FGDs were mixed of satisfaction and dissatisfaction with job experience.

Conclusion: Job description of Lady health workers is not too much as they are being worked but coping mechanism made it facilitate to work smoothly.

Keywords: Family planning program, lady health worker, coping mechanism, workload
\end{abstract}




\section{Introduction}

Lady health worker program is working for provision and supervision to maternal and child to their health services. National program of Family planning and Primary Health program (NPFP\&PHP) was introduced in 1994(1). Work related stress lead the individual towards various sign and symptoms like sadness, worried and depression. (2). Work of LHW is to visit homes, communities as prescribed in their job description (3). Previous studies has proven that work of Lady Health Work is high-risk at mental and physical hurdles (4) At initial stage, most of the Lady health workers are suffering from stress due to inexperienced (5). It has $100 \%$ incidence rate towards biological disturbance (6). World Health Organization called it epidemic, The International Organization of Labor lobbed as it carries negative impact on the national gross production (7). Workplace environment, organizational factors and utilization of EAPs are the workplace stressors (8). In a study (2008), it was proven of having $1 / 4$ significant occupational stress (3).

We assessed association of work stress with demographic variables and to explore the coping mechanisms of LHWs to deal with work stress

\section{Methodology}

Cross sectional mixed method study was conducted in Three Taluka of Jacobabad District i.e Jacobabad, Gharhi Khairo and Thul among Lady Health Workers. Study duration was 5 months (Nov 2016- March 2017). Data sources were cross sectional survey in which SRQ-20 were used for quantitative study whereas Qualitative component of the study included 3 focus group discussions (3 FGDs were conducted with 8 participants and total participants were 24). Qualitative subcomponent was included to triangulate the data from main quantitative component of the study. For this purpose 3 FGDs were organized. The respondents were previously selected from the LHWs included in the survey. 75 samples were taken through Simple Random Sampling based on the prevalence rate. SRQ- 20 questionnaire were used which is open access WHO reliable and validated tool as well translated into many languages. Socio-Demographic variables included as age, education, marital status, monthly income and job experience. LHWs working and attached with MCH Centers of Jacobabad and having at least one year of work experience were included whereas those who were on long leave or unavailable were excluded. Quantitative data was coded and entered into SPSS-21 version for analysis. Both infertial statistics methods (Chi Square) and descriptive statistics methods (summary, tables, graphs, mean, percentage, frequencies etc) were applied. Inductive content analysis method as well triangulation method were used to analyses the qualitative data 3 FGDs. Relevant results were categorized. After approval from Internal Review Board (IRB) of Health Services Academy (HSA) Islamabad, supporting letter sought towards concerned District Administration. It was ensured that the rights of research participants were protected, to alleviate any fears volunteers were informed about full autonomy and free to withdraw at any stage. The purpose was explained and informed written consent was obtained from participants. FGDs were conducted according to good practice abiding ethics of research.

Specificity, sensitivity, reliability and validity of SRQ-20 WHO tool Stress was assessed as expressed in the form of psychological stress, using the Self reporting Questionnaire, briefly known as SRQ-20. The SRQ-20 is a tool to identify mental distress including psychological and somatic symptoms in the general population. It is consisted of 20items and yields YES/NO answers (1). Scale has been validated $(9,10$, 11). Further 20 items of SRQ-20 categorized into 3 different labeling Physiological alterations, Nervousness and subjective perception items are distributed according to the contents as below given:

Results

Socio-Demographical Variables

In all 75 LHWs were included in the study. The table shows sociodemographics

Table of demographical statistics age, income and job experience is shown below
Table 1-Demographic characteristic

\begin{tabular}{|l|c|c|}
\hline \multicolumn{2}{|l|}{ Demographical Statistics } & Mean \\
\hline Demographical & 35.59 & \pm 7.995 \\
\hline Age (Years) & 20500 & \pm 438 \\
\hline Monthly income (Rs.) & 4.87 & \pm 3.599 \\
\hline Job experience: (Years) & Frequency & Percent \\
\hline Age & 22 & 29.3 \\
\hline $22-31$ & 37 & 49.3 \\
\hline $32-41$ & 11 & 14.7 \\
\hline $42-51$ & 5 & 6.7 \\
\hline $52<$ & 19 & 74.7 \\
\hline Monthly income & 56 & 25.3 \\
\hline Less than 20000 & \multicolumn{2}{|}{} \\
\hline More than 20000 & 42 & 56.0 \\
\hline Experience (years) & 23 & 30.7 \\
\hline 2 & 10 & 13.3 \\
\hline 7 & & \\
\hline 12 & & \\
\hline
\end{tabular}

Age: The majority of the respondents' were $32-41$ years (49.3\%)

Education: Almost half(44\%) were educated till Intermediate.

Marital Status: Majority of the respondents were married 43 (75.3\%) while $26.7 \%$ were unmarried.

Monthly income: Monthly income of the respondent less than 2000 PKR is $74.7 \%$

Experience in years: Appointment of LHWs was hired in phases depends upon the call of the recruitment. Such relation to this study here found experience of 2, 7 and 12 years. Majority of the LHWs were young enough in their experience 2 years $(56 \%)$

Items of the SRQ-20: Items of the sub-scale physiological alteration, nervousness and subjective perception are shown below:

Table 2- Distribution of SRQ

\begin{tabular}{|c|c|c|}
\hline Physiological Alteration & YES \% & NO $\%$ \\
\hline Headache & 57.3 & 42.7 \\
\hline Appetite badly & 49.3 & 50.7 \\
\hline Sleep badly & 53.3 & 46.7 \\
\hline Digestion & 54.7 & 45.3 \\
\hline Uncomfortable stomach & 38.7 & 61.3 \\
\hline \multicolumn{3}{|l|}{ Nervousness } \\
\hline Frightened & 49.3 & 50.7 \\
\hline Hands shake & 32.0 & 68.0 \\
\hline Nervous & 49.3 & 50.7 \\
\hline Crying & 48.0 & 52.0 \\
\hline \multicolumn{3}{|l|}{ Subjective Perception } \\
\hline Thinking clearly & 42.7 & 57.3 \\
\hline Unhappy & 49.3 & 50.7 \\
\hline Difficult to enjoy activities & 49.3 & 50.7 \\
\hline Difficult to make decisions & 54.7 & 45.3 \\
\hline Daily work suffering & 46.7 & 53.3 \\
\hline $\begin{array}{l}\text { Unable to play part in life } \\
\text { issues }\end{array}$ & 48.0 & 52.0 \\
\hline Lost interest in things & 50.7 & 49.3 \\
\hline Feel tired all the time & 49.3 & 50.7 \\
\hline Easily tired & 53.3 & 46.7 \\
\hline Worthless person & 34.7 & 65.3 \\
\hline Thoughts of ending life & 52.0 & 48.0 \\
\hline
\end{tabular}

All the three outcome variables i.e. physiological alteration, nervousness and subjective perception were compared with all 5 items of socio-economic-demographic i.e. age, education level, marital 
level, monthly income and job experience. The results of chi square are as under:

Table 3-Association of socio-demographic characteristics with outcome variables

\begin{tabular}{|l|l|l|}
\hline Variables & $\mathbf{p}$-Value & \multicolumn{1}{c|}{ Results (Decision) } \\
\hline $\mathrm{A}^{*}$ and $\mathrm{P}^{*}$ & .523 & Not significant (No association) \\
\hline $\mathrm{A}^{*}$ and $\mathrm{N}^{*}$ & .534 & Not significant (No association) \\
\hline $\mathrm{A}^{*}$ and $\mathrm{S}^{*}$ & .000 & Significant (Association found) \\
\hline $\mathrm{E}^{*}$ and $\mathrm{P}^{*}$ & .045 & Significant (Association found) \\
\hline $\mathrm{E}^{*}$ and $\mathrm{N}^{*}$ & .092 & Not significant (No association) \\
\hline $\mathrm{E}^{*}$ and $\mathrm{S}^{*}$ & .006 & Not significant (No association) \\
\hline $\mathrm{M}^{*}$ and $\mathrm{P}^{*}$ & .108 & Not significant (No association) \\
\hline $\mathrm{M}^{*}$ and $\mathrm{N}^{*}$ & .874 & Not significant (No association) \\
\hline $\mathrm{M}^{*}$ and $\mathrm{S}^{*}$ & .252 & Not significant (No association) \\
\hline $\mathrm{MI}^{*}$ and $\mathrm{P}^{*}$ & .698 & Not significant (No association) \\
\hline $\mathrm{MI}^{*}$ and $\mathrm{N}^{*}$ & .862 & Not significant (No association) \\
\hline $\mathrm{MI}^{*}$ and $\mathrm{S}^{*}$ & .381 & Not significant (No association) \\
\hline $\mathrm{E}^{*}$ and $\mathrm{P}^{*}$ & .391 & Not significant (No association) \\
\hline $\mathrm{E}^{*}$ and $\mathrm{N}^{*}$ & .545 & Not significant (No association) \\
\hline $\mathrm{E}^{*}$ and $\mathrm{S}^{*}$ & .011 & Significant (Association found) \\
\hline
\end{tabular}

$\mathrm{A}^{*}=$ Age, $\mathrm{E}^{*}=$ Education, $\mathrm{M}^{*}=$ Marital Status, $\mathrm{MI}^{*}=$ Monthly income $\mathrm{E}^{*}=\mathrm{Job}$ Experience, $\mathrm{P}^{*}=$ Physiological alteration, $\mathrm{N}^{*}=$ Nervousness and $\mathrm{S}^{*}=$ Subjective perception

From the above table it is interpreted that among the 15 variables only 3 found as significant, i.e. old-subjective perception, educationphysiological alteration and job experience-subjective perception. Association in between subjective perception, education-physiologica alteration and job experience-subjective perception were found. Such association may alter to one another

Qualitative Component of Coping Mechanism

Focus Group Discussions

3 FGDs have been conducted to explore the coping mechanism of the LHWs to deal with workplace stress. Each FGD comprised of 8 members among them other members discussed on the topic Performance of work decreases due to workplace stress and also its production decreases day by day. The LHWs devised their stress coping strategies. One LHW was of the view "This is our duty and responsibility to perform all work, if we will not do; officials will pressure us to do within limited time" (LHW of 35 old, 2 years exp, Thul). Another remarked "We might leave this job if other jobs we ge but this time it is better to do job until and unless we get another. We are working hard with bearing al the threats and we are not saying even a single word to them" (LHW of 42 old, 7 years exp, Garhi Khairo).A new LHW remarked that, "After completing our field work we are being exhausted in few circumstances we are denying them and arguing that we will get leave and mostly we are habitual of it to do. After field work we are doing written work as formality and we are almost seeking support not to send us in the fields work" (LHW of 38 old, 2 years exp, Jacobabad).

Describing their positions and coping the quotes of some LHWs are as follows,

"Jekadhen asan khe bhe kaa nokrii milandii te zror kanda see, hit tee asaaan khe tamam gahnooo kammm aaa un $\mathrm{g}$ kare dadi pareshin thendii aa" one respondant expressed (LHW of 29 old, 2 years exp, Thul)

(Translation: whenever I will/will get another job surely I/we will join that, here is too much overload to work due to that $\mathrm{I} /$ we is/ are getting stressed)

"Sarkari Nokri aa karneee teee aaaheee asaaan jekdheeen kadhenn ne bee kayuu tee poeee bee subhaane te uhooo eee kaaam karnoo pawandoo aaa " one of the senior most respondent expressed(LHW of 47 old, 7 years exp, Garhi Khairo)

(Translation: this is govt. job we have to do; if we are doing today definitely we have to do it tomorrow)

"If we live in our homes definitely we will be suppressed but this is better for us to avail opportunity in this regard. Our job is like an entertainment activity. Many times out officers told us that we will be merged into health department on regular basis and will get pension as well as other benefits like other employees" (LHW of 34 old, 2 years exp, Thul)

"To serve the humanity is a good thing we are serving our neighbor and they all are respecting us. We are used to do work on regular basis within stress environment" (LHW of 39 old, 7 years exp, Garhi Khairo) "Asaan khe paaaree wara sub doctor chawanda aaahin, chaaa ihaa asann gee izatt kon aaahe? Tamam dado sutho lagando aaa per nokri dadi dukhiii te aaaheee". A girl expressed (LHW of 23 old, 2 years exp, Jacobabad)

(Translation: Most of the relatives called us as Doctor; we are feeling too good, though our job description is also not easy)

"Kadheeen kadheeen asan paaan meee kachehri kandaa aahyuu tee pareshanni gat the wendiii aa". A junior most girl expressed (LHW of 39 old, 7 years exp, Garhi Khairo)

(Translation: sometimes we are sharing our ideas with each other this sharing is decreasing our stress)

"We are doing our work till 1 pm with full conscious and in relaxed environment, later on we are being exhausted then we are just doing our formalities of the day to complete different tasks given by the authority"(LHW of 30 old, 2 years exp, Thul)

"In the field no one wanted to go in this summer or winter condition without having good facility of transport. Few times we deny to our officer that we cannot do much. In this regarding we are meeting with our friends but visiting to the families during our duty time" (LHW of 36 years, 02 years exp, Garhi Khairo)

"Lady Health Worker jehrooo kum koiii b nathooo kare sagheee, uhaaa asaaan khe khaberr aaa ketro kum sabar saa kandaa ahyu" (LHW of 44 years, 7 years exp, Thul)

(Translation: no one can do work of the Lady Health Worker, we are well aware of it what we are facing a lot)

"Allah khe khaber aaa asaan keeeaaan nokri kandaaa ahhyooo, Buuuus kuch ne karan khaaa karan bhalo aaaa par pareshani thendiii aaa sukooon konheee" (LHW of 29 years, 2 years exp, Garhi Khairo)

(Translation: Allah knows better how we are doing job, doing something is better than nothing. Sometimes getting stressed rather than to be relax)

Following themes were emerged

Table 4. Main themes from the Focus Group Discussions

\begin{tabular}{|c|c|}
\hline $\begin{array}{c}\text { Themes of Coping } \\
\text { Mechanisms }\end{array}$ & Sub-Themes \\
\hline Job as duty & $\begin{array}{l}\text { - } \quad \text { This is our part of job description } \\
\text { - We are working hard } \\
\text { - } \quad \text { We are asking for the support } \\
\text { - We are accepting responsibilities } \\
\text { We are praying all the time }\end{array}$ \\
\hline Job as pressure & $\begin{array}{l}\text { - We are helplessness, Constrains and in } \\
\text { compulsion we have to do } \\
\text { - We are under the pressure of the job } \\
\text { - We are doing formalities } \\
\text { - Many time we are controlling our selves }\end{array}$ \\
\hline Defense mechanisms & $\begin{array}{l}\text { - To do something is better than nothing } \\
\text { - } \quad \text { To serve the humanity is to service of Allah } \\
\text { - } \quad \text { Meanwhile we are visiting homes of the } \\
\text { - } \quad \text { We have hope for better in future } \\
\text { - } \quad \text { Sometime we are using sense of humor }\end{array}$ \\
\hline
\end{tabular}

Discussion

This study, which is aim to describe to demonstrate relationship between demographics and stress among the LHWs of Jacobabad working in the $\mathrm{MCH}$ centers, has brought at front the common factors or situations that is usually describes the load of the work. Findings of this study suggest that daily work environment of work of LHW is expose to stressful situations. The study is important to conduct in a sense that it identifies the overweight expectations or demands from the nurses as compare to their capabilities and skills what they have acquired during their training periods and learn through experience of her job (12). In this study the findings show that the working LHWs are mature and young, their means age is $35.59+7.995$, their average of 
monthly income is round about 20500 Pak. rupees and the experience of their job is 2, 7 and 12 years due to having govt job, the recruitment was done on phases depends upon the announcement of the opportunities in this discipline. The lack of service structure as well continuation of their job is not present due to that they are not taking interest while performing their duty (13). The findings are interrelating many to other studies in different settings like hospitals workers working in China, Japan, Korea, Thailand, and USA. All indicate workload and dealing with death and dying to be two most common workplace stressors (14). Study shows that half of the LHWs are intermediate in their studies while as having graduation and masters' degrees are less in number i.e. 10 and 9. Study also reveals that married LHWs are the highest (57\%), while windows, divorced and separated are also included in the study. Study exposes that $68 \%$ of LHWs are under workplace stress, among them $37.3 \%$ are in moderate and $30.7 \%$ are in severe stress of workplace. It might be due to the field work or others polio and nutrition campaigns which are running in the concerned district. Qualitative study also reveals that personal issues, perception issues, salary issues, transport issues, family burden and social issues are the leading factors towards workplace stress. Cope mechanism is present in human nature to defend him/her, either directly or indirectly to replace to solve the matters and to prevent from the anxiety for the normalization of daily life. (Sigmund Freud). During the focus group discussions they express duty as responsibility, and they also declare that to serve the humanity is to service of Allah, among them few of them express as workload, too much exhaust and they are defending their job by getting leave or absenteeism in nature. Among them a few expresses as something is better than nothing to do rather than to waste time at home freely. Few of them are happy by visiting the homes of the community families because their relatives are also in that community where they are going for the visit. The findings of the study suggest that about more than half of the LHWs have some kind of work related stress as indicated by the physiological alteration, nervousness and subjective perception. Findings suggest that there are certain variables socio-economic statuses, subjective experience, job experience, age and education which increase vulnerability of a LHW for work related stress. Main identified issues leading towards workplace stress include less incentives, low salary, failure in quality trainings and failure of job structure

\section{Conclusions}

The research study concluded that job of LHW is a stressful in nature with interesting coping mechanisms. To our knowledge, this is the initial effort to research in Sindh specially Jacobabad to assess the workplace stress as well their factors including their coping mechanism.
Recommendation and Way forward

Coping trainings should be introduced, Coping mechanism can be compensated through provision of handsome salaries, and incentives and Coping strategy should be introduced

References

1. Haq Z, Iqbal Z,Rahman A, Job stress among community health workers, BMC (2008)

2. Robers R, Paula G, Grosch j.W. Alleviating job stress in nurses. Medscape Public Health \& Prevention (2012)

3. Haq Z, Iqbal Z, Rahman A. Job stress among community health workers: a multi-method study from Pakistan. Int J Ment Health Syst [Internet]. 2008;2(1):15.

4. Largo-Wight E, Chen WW, Dodd V, Weiler R. Healthy Workplaces?: The Effects of Nature Contact at Work on Employee Stress and Health. Public Health Rep. 2011;126:12431 .

5. Urbanetto J de S, da Silva PC, Hoffmeister E, de Negri BS, da Costa BEP, de Figueiredo CEP. Workplace stress in nursing workers from an emergency hospital: Job Stress Scale analysis. Rev Latino-Americana Enferm [Internet]. 2011;19(5):1122$113110 \mathrm{p}$

6. Tanya I., Job stress in the nursing Profession, The influence of organisational and environmental conditions and job characterstics; international journal of stress management (2005)

7. Azzone R. Workplace stress, organisational factors and EAP utilization, NIH Public Area (2015)

8. Dagget T. Job stress among nurses working in Jimma Zone public hospitals, South West Ethopia; BMC Nursing (2016)

9. Hussain N., Chaudhry N Et al. Validation of the SRQ in British pakistani and White Eurpean Population in the UK, Journal of Affective Disorders (2015)

10. Westhuizen C., Williams J., Validation of SRQ 20-items for use in a low and middle income country emergency cantre setting; International J. mental health Addiction (2016)

11. Taun T. Harpham, Houng NT., Validity and reliability of the SRQ 20 items in Vietnam;, Hong Kong J. Psychiatry (2004)

12. Parpio Y. Farooq S., Factors associated with stress among adolescents in the coty of Nawab Shah; J Pak Med. Association (2005)

13. Khan K. Gulzar S. Yahya F., Cruicial Factors Affecting Stress; A study among UG in Pakistan; International journal of Asian social sciences (2014)

14. Ali WU, Raheem AR, Nawaz A, Imamuddin K. Impact of Stress on Job Performance: An Empirical Study of the Employees of Private Sector Universities of Karachi, Pakistan. Res J Manag Sci [Internet]. 2014;3(7):14-7. 